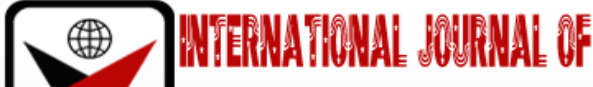

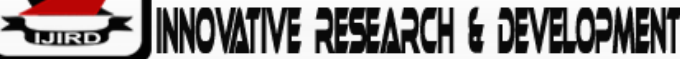

ISSN 2278 - 0211 (Online)

\section{Does Ongoing Feedback Based on Evaluation of Nurse Educator: Improve the Teaching Learning Skills in B.Sc. N Program in Karachi, Sindh, Pakistan?}

Almas chapsi
Vice Principal, College of Nursing, Ziauddin University, Pakistan
Husan Bano Channar
Assistant Professor, Liaquat University of Medical and Health Sciences (LUMHS), Pakistan
Ruth K Alam
Principal, Holy Family School of Nursing, Pakistan

\section{Abstract:}

Background

Objective: To determine the effectiveness of ongoing feedback based on evaluation of nurse educators by the students in colleges of Nursing affiliated with Liaquat University of Medical and Health Sciences, (LUMHS) Jamshoro.

Purpose: To improve the nursing education through feedback based on evaluation of teaching and enhances the evaluation methodology of teaching in nursing education

Methodology: An experimental research design was used to assess the effectiveness and improvement of ongoing evaluation of nurse educator. Randomized control trail was done. Subjects were assigned to a group randomly. Random assignment accomplished by obtain a list of faculty members from both private and public-sector institutes of nursing, then the random sample of the desired size was draw. 18 Nurse Educators randomly were selected from different institutes for study, out of nineteen 9 were selected randomly for experimental and 9 for control group. Data collected by using pre-structured questionnaire composed of different parts

Analysis:

Data was analyzed on SPSS version 20. Chi square test was used for categorial variable. T- test of significant was used to find the association between independent variables and outcome variable $95 \%$ confident interval was calculated.

Results :

Descriptive statistics of the study Mean score with standard daviation achieved by Wilxcon $w$ test that is 46.3 ? 9.5, of control group and 37.4 [ 10.12 of experimental group with $p=1.3 \mathrm{~ns}$. Chi square test was use for quantative analysis.

Conclusion:

Ongoing evaluation can be a positive experience for both the nurse educator and the evaluator's. The challenge for evaluator's is to make the evaluation process a meaningful experience. Based on the study findings, improving nursing student's achievements as well as teaching effectiveness require feed back by student to nurse educator. Educators encourage active learning and involve students in the educational process

Keywords: Ongoing feedback, nurse educator, students, teaching, learning, effectiveness

\section{Background}

The aim of nursing education is the transmission of nursing knowledge and skills associated with nursing practice. To enhance nursing skills generally nursing education designed on the three domains of learning that are cognitive, affective, and psychomotor (Alice, 2005). Evaluation on ongoing bases is considered as one of the ways to enhance nursing education. Researchers endorsed that over the time the interest in evaluating teaching effectiveness has increased. Furthermore, the acceptance to the need to evaluate teaching has consistently grown. However, definition of effective teaching is still challengeable (Applin et al, 2011). Teaching is an art. It is a complex and demanding activity that requires mastery over content, classroom control, techniques of organization, and command of teaching skills (Arthur et al, 2003). Provision of faculty development related to teaching and assessment strategies is widely perceived to be the essential ingredient. An effort to introduce new curricular approaches modifies the educational environment in academia (Canniford \& Young, 2015). 
Analyses of the outcomes of efforts to revise health professions curricula have identified the availability and effectiveness of faculty development as a predictor of the success or failure of reform initiatives (Curran et al, 2010). Regarding the Qualities of Effective Teachers, Stronge (2002) synthesizes research to identify specific teacher behaviors that contribute to student achievement, rather than looking at outside factors example demographics, District leadership, and state mandates, Stronge focuses specifically on strategies that could be controls teacher's own preparation, personality, and practices (Stronge, 2002). Still there is need of researchers to identify the specification such as definition of effective teaching skills, beliefs about the teaching and learning process educators and their student's hold, criteria to assess teaching effectiveness (Diefenbeck, 2015). Furthermore, right person to evaluate the various aspects of teaching, and last but not least the important elements of assessment of effective teaching in nursing education (Fitzpatrick, 2004). Evaluation is an effective means of measuring teaching and learning performances improving the teaching process. It can be used to trace both teaching procedures and learning progress through comparing their teaching to the syllabi and any other documents, teachers can evaluate their teaching and adjust their teaching strategies to meet the learners' needs and the requirements of the program (Fluit et al, 2010). The evaluation of teaching facilitates attainment of several important objectives: to improve the quality of teaching, to assist faculty to evaluate their own teaching, to fulfill the criteria of the academic institution, to improve accountability in education, and to identify the content areas for faculty development programs (Emamzadeh, 2014). Evaluation of teaching is important in the teaching-learning process. The review of evaluation data can identify areas of effectiveness, as well as problem areas in teaching. Ongoing feedback evaluation, which occurs during the progression of an action, is a widely used means of judging the progress and achievements of programs (Hasheesh, 2011). Developers and supervisors often use the results of their evaluations to rate programs. Evaluations may help directors decide such matters as ranking teachers, funding the programs, and promoting teachers. In some cases, evaluations include input from colleagues and supervisors, with teachers and learners playing only a passive role in the evaluation process (Houser, 2008). Many novice teachers focused on teaching, rather than on learning. However, in higher education, focus increasingly is on learners and learning, rather than teachers and teaching. The nursing faculty is insufficient in Sindh. So private sector is hiring visiting faculty in their institutions. Most of the Nursing Faculty themselves are also doing BScN in addition to their teaching responsibility. Because of this reason, ongoing feedback evaluation is very important to check effectiveness of teaching and learning strategies (Heshmati-Nabavi, 2010). This study is the first research endeavor into teaching effectiveness evaluation in the faculty of nursing in Sindh. The purpose of this study is to determine the effectiveness of ongoing evaluation of nurse educators at private and public sector by the students in nursing institutions affiliated with Liaquat University of Medical and Health Sciences (LUMHS) Jamshoro, Sindh.

\section{Methodology}

Eighteen Nurse Educators randomly were selected from different institute of nursing for study out of nineteen 9 were selected randomly for experimental and 9 for control group.

Study Setting and study participants. Ongoing evaluation form filled by students and then feed back was given to nurse educators. The duration of the data collection was four months. Nursing faculties of the colleges were participants and the Study was conducted in both public and private sector. Randomized control trail was done to meet the objectives. Subjects were assigned to a group randomly. Random assignment could be accomplished by obtained a list of faculty members from both private and public-sector institutes of nursing then draw random sample of the desired size. Data was collected by using pre-structured questionnaire composed of different parts. Measurement of exposure (questioner consist on demographic data Age, sex, training, teaching experience, name of institute, professional qualification) and evaluation tool filled by students. Measurement of outcome (teaching check list was used as evaluation tool, to assess the effectiveness of ongoing feedback).

\subsection{Ethical Consideration}

Study approval was taken from ERC. (Ethical review committee JPMC) Data was obtained anonymous questioner. The questionnaire was translated in to National Language also. Confidentiality was managed at each step of the study and the data was kept in locked cabinet only the Principal Investigator was given access.

\subsection{Intervention}

- 0 Session: Met with principals, get institutions permission and taken participant list. Then consent form signed by nurse educators.

- $\quad 1^{\text {st }}$ Session: Evaluation form was filled on visits one by students and provided feed back to participant.

- $\quad 2^{\text {nd }}$ Session: After 15 days, again evaluation was done with feedback.

- $\quad 3^{\text {rd }}$ Session: After 15 days of $2^{\text {nd }}$ session assessed the effectiveness of feedback and compiled the result

\subsubsection{Stage 1}

An initial ongoing evaluation will be carried out in the first week. For the base line assessment, the researcher was asked to participants about the Demographic data, and explained the process of research, and signed the consent. Teaching evaluation form filled by the eligible candidate and gave feedback to Nurse Educator. The researchers were actively involved in collecting and analyzing data periodically during the research. 


\subsubsection{Stage 2}

A formal evaluation was done to measure the performance of the nurse educator. The learner was observed for their performance. Student responses were recorded by the teacher questions. The roles of learners play in the discussion during lecture. Learner (nurse educator) was received feedback from the students' responses on corrections. After 1 session feedback, researchers were observed again and done evaluation.

\subsubsection{Stage 3}

Previously data collection was studied to see the goal attainment. Comments and feedback was analyzed and shared with the participant. Final evaluation was done and feedback was given to nurse educators.

\section{Results}

Data was analyzed using SPSS version 20. Frequency with percentage was calculated for catagorial variables i.e gender, academic and professional qualification, type of institution, while mean and standerd deviation was used for continues variable i.e experince, age, education of faculty. The Data was displayed through graph such as pie chart ,bar graph for catagorical. Chi square test was used for categorial variable. T test was used to find the association between independent variables and outcome variable $95 \%$ confident interval was calculated.

All institute of nursing those who are offering post RN BScN degree programe was selected in the study, after taking written permission from the head of institutes the list of nurse ducators was obtaiend from the institutes both private and public sector. 21 partcicipants were approcehed out of which 18 participants responded .

\begin{tabular}{|c|c|c|c|c|}
\hline Variables & $\begin{array}{c}\text { Control group } \\
(n=9)\end{array}$ & $\begin{array}{c}\text { Experimental group } \\
n=9\end{array}$ & p-value & Test \\
\hline Mean age (years) & 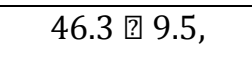 & 37.4 ? 10.12 & $\mathrm{p}=1.3 \mathrm{~ns}$ & Wilcoxon W \\
\hline Median age (years) & 50 years & 35 years & $\mathrm{p}=0.07$ & t-test \\
\hline \multicolumn{5}{|l|}{ Gender } \\
\hline Male & 4 & 6 & \multirow[t]{2}{*}{$\mathrm{p}=0.63$} & \multirow[t]{2}{*}{ Fisher's Test } \\
\hline Female & 5 & 3 & & \\
\hline \multicolumn{5}{|l|}{ Marital Status } \\
\hline Married & 6 & 8 & \multirow[t]{2}{*}{0.57} & \multirow[t]{2}{*}{ Fisher's Test } \\
\hline Un-married & 3 & 1 & & \\
\hline \multicolumn{5}{|l|}{ Nature of Employment } \\
\hline Full Time & 4 & 8 & \multirow[t]{2}{*}{0.13} & \multirow[t]{2}{*}{ Fisher's Test } \\
\hline Part Time & 5 & 1 & & \\
\hline \multicolumn{5}{|l|}{ Academic Qualification } \\
\hline Postgraduates (M.A.) & 2 & 2 & \multirow[t]{5}{*}{0.537} & \multirow{5}{*}{$\begin{array}{l}\text { Pearson } \\
\text { chi-Square }\end{array}$} \\
\hline Graduates (B.Sc.) & 1 & 0 & & \\
\hline Graduates (B.A.) & 0 & 2 & & \\
\hline Intermediate & 5 & 4 & & \\
\hline Matric & 1 & 1 & & \\
\hline \multicolumn{5}{|l|}{ Professional qualification } \\
\hline BSc N & 7 & 9 & \multirow[t]{2}{*}{0.47} & \multirow[t]{2}{*}{ Fisher's Test } \\
\hline MSc. N & 2 & 0 & & \\
\hline \multicolumn{5}{|l|}{ Institution } \\
\hline JPMC & 1 & 3 & \multirow[t]{4}{*}{0.122} & \multirow{4}{*}{$\begin{array}{c}\text { Pearson } \\
\text { chi-Square }\end{array}$} \\
\hline ST. James & 1 & 4 & & \\
\hline Karachi King & 5 & 1 & & \\
\hline Life saving & 2 & 1 & & \\
\hline $\begin{array}{l}\text { Mean Teaching experience } \\
\text { (years) }\end{array}$ & 3.2 ? 1.2 & 4.7 目 1.9 & $\mathrm{p}=0.07 \mathrm{~ns}$ & Wilcoxon W \\
\hline
\end{tabular}

Table 1: Descriptive Variables in Control and Experimental Groups 


\subsection{Demographic Data of the Participants}

There were total 18 participants 9 in the control group and 9 in the experimental group. The mean age of control group was 46 years whereas, experimental group was 37 years. Majority of the participant's age were 35 years. Most of the participants were married. 16 participants were having BSc $\mathrm{N}$ degree and two of them had completed their MScN. The percentage of participants with full time job was higher than the part time of four institute of nursing that was $66.7 \%$. Majority of the participant's teaching experiences was between 1 to 5 years.

The analysis of results showed that $55.6 \%$ need improvement in starting class on the given time. After second intervention the percentage decreases to $40 \% .44 .4 \%$ participants' paced topic effectively. After second intervention the percentage increases to $61.1 \%$. 61.1\% needs improvement in demonstrating the topic in sequenced logical manner. After second intervention the percentage decreases to $40 \%$. 44.4\% needs improvement in summarizing topic. After second intervention the percentage remains same. 55.6\% needs improvement in presenting content clearly. After second intervention the $55.6 \%$ present content effectively. $50 \%$ were using good examples in class to clarify topics. After second intervention the percentage increases to $60 \%$. 61.1\% educators give varied explanations to respond to student's questions to clarify the points. $44.4 \%$ participants emphasized the important points. After second intervention the percentage increases to $70 \%$. $50 \%$ needs improvement in using visual aids. After second intervention the percentage decreases to $38 \% .44 .4 \%$ educators had appropriate voice volume and inflection. After second intervention the percentage increases to $66 \% .61 .1 \%$ educators' shows enthusiasm while discussions. After second intervention the percentage increases to $66 \%$. $72.2 \%$ effectively response to student behavior. After second intervention the percentage decreases to $80 \% .83 .3 \%$ encourage students to raise questions. After second intervention the percentage increases to $90 \% .77 .8 \%$ asked questions to understand the level of students. After second intervention the percentage remains same. $50 \%$ provides enough opportunities for students to interact together to discover things. After second intervention the percentage increases to $60 \%$. 61.1\% shows the course content relevancy effectively. After second intervention the percentage increases to $70 \%$. 55.6\% had command on their subject. After second intervention the percentage increases to $60 \% .72 .2 \%$ showed respect to the student's question. After second intervention the percentage increases to $80 \%$.

\section{Discussion}

To the best of our knowledge this study is the first attempt in Pakistan looking effectiveness of feed back to nurse educator by post RN BSc N Degree students. Teaching Effectiveness: Defining the Construct, why is measuring teaching effectiveness so important? Because the evidence produced is used for major decisions about our future in academe. There are two types of decisions: formative, which uses the evidence to improve and shape the quality of teaching, and summative, which uses the evidence to "sum up" our overall performance or status to decide about our annual merit pay, promotion, and tenure. The former involves decisions to improve teaching; the latter consists of personnel decisions. As faculty, we make formative decisions to plan and revise our teaching semester after semester. Summative decisions are final and they are rendered by administrators or colleagues at different points in time to determine whether we have a future. These decisions have an impact on the quality of our professional life. The various sources of evidence for teaching effectiveness may be employed for either formative or summative decisions or both (Ronald \& Berk, 2005).

The study is investigating the relationships of central teaching characteristics to student learning. These characteristics include classroom climate, class organization, instructional practice, class interaction, mastery of content of the teacher, attitude of the teacher, emotional support for the students, and teacher's knowledge. For the study, the researchers worked with the post RN BScN students and nurse educators for the period of four month. Three times interventions were done to collect the evidence on a number of measures of teaching effectiveness. The Measures of Effective Teaching (MET) project seeks to develop an array of measures that will be viewed by teachers, unions, administrators and policymakers as reliable and credible indicators of effective teaching. By determining exactly what measures predict the biggest student achievement gains, the MET project will give teachers the feedback (including exemplary practices) they need to improve. In addition, a greater understanding about which teaching practices, skills and knowledge positively impact student learning will allow the institute to develop teacher evaluation systems that will help strengthen all aspects of teaching from recruitment through retention (Kashaninia, 2013).

Effective teaching requires nursing educators shift from a teacher centered to student - centered approach, which can foster independence in learning, creative problem- solving skills, a commitment to life- long learning and critical thinking. Nurse educator are often design to serve two purpose one is to measure the teacher competence and another is to foster professional development and growth. Evaluator should consider a variety of teaching skills. If the evaluators use several sources of information about a teacher's performance they can make a more accurate evaluation .class observation is one of the common activity. This is for by the most common form of data collection for evaluation. The goal of class observation is to obtain a representative sample of a teacher's performance in the class room. Evaluators can not accomplish this goal with a sample of only a few hours of observation or with an observation of only one class. Observation can be formal and planned or informal and unannounced. Both forms of evaluation can provide valuable information (Salsali, 2005). A post observation can give teachers feed back on their strengths and weaknesses. Evaluator must remember to deliver the feed back in a constitutive way and suggest changes that make sense to the teacher. It is important to maintain praise and criticism and give enough feed back to be useful but not so much that the teachers are overwhelmed (Kong, 2014). Educators and students reported that most 
of the criteria for evaluating the inputs, the process, and the outputs of teaching were of "great" or "very great" importance. Also, they shared the same perceptions regarding the importance of the four categories of criteria used in the current study that were ranked in the following order: inputs into the teaching/learning process, instructor teaching behavior: student engagement, instructor teaching strategies, and instructor helping behavior. These findings are supported by the available literature. Researchers endorsed that teacher behaviors such as knowledge of subject-matter and instructor commitment (inputs to the teaching/learning process), the ability to inspire interest, instructor communication skills, and instructor use of organized material (student engagement variables), instructor flexibility and instructor ability to provide clear explanations (instructor teaching strategies), along with instructor enthusiasm, teacher-student relationship, and instructor ability to give students criticism in an appropriate manner (instructor helping behaviors) are all related to effective teaching (LoBiondoWood, 2013).

Important elements for evaluating teaching effectiveness were consistent with several studies reviewed in the literature which showed that instructor personality, instructor experience, and the psychological environment were important variables in teaching effectiveness as perceived by educators and by students (Mansoureh, 2015). In contrast with the literature, students' and educators' Perceptions in this study showed that teacher academic rank was viewed as an important variable for evaluating teaching effectiveness.

\section{Conclusion and Recommendations}

Ongoing evaluation can be a positive experience for both the nurse educator and the evaluator's. The challenge for evaluator's is to make the evaluation process a meaningful experience. Based on the study findings, improving nursing student's achievements as well as teaching effectiveness require feed back by student to nurse educator. Educators encourage active learning and involve students in the educational process. As for effective teaching, students must read, write, and discuss the material they are learning. They must also participate in high order thinking exercises, such as analysis, synthesis, and evaluation. Nurse educators are responsible for creating good environment in classroom settings that facilitates student learning and the achievement of desired cognitive, affective, and psychomotor outcomes. To facilitate learning effectively, the nurse educator implements a variety of teaching strategies appropriate to learner needs, desired learner outcomes, content, and context. Nurse educators must recognize multicultural, gender, and experiential influences on teaching and learning. Nurse educators practice skilled oral, written, and electronic communication that reflects an awareness of self and others, along with an ability to convey ideas in a variety of contexts shows enthusiasm for teaching, learning, and nursing that inspires and motivates students and demonstrates interest in and respect for learners uses personal attributes (e.g., caring, confidence, patience, integrity and flexibility). Nurse educator serves as a role model of professional nursing. Nurse educator should assist learners to develop the ability to engage in thoughtful and constructive self and peer-evaluation (Mansoureh, 2015).

For the Continuous Quality Improvement (CQI) the Nurse educators recognize that their role is multidimensional and that an ongoing commitment to develop and maintain competence in use knowledge of legal and ethical issues relevant to higher education and nursing education as a basis for influencing, designing, and implementing policies and procedures related to students, faculty, and the educational environment The need for greater accountability and improvement in the quality of teaching has become a major issue in higher education in recent years (Owen, 1992; Mansoureh, 2015). In response to this need, both governments and universities have attempted to institute policies and practices designed to measure, encourage and reward 'good teaching (Patricia, 2002). The researchers of the present study recommend further researches to be conducted at nursing colleges.

\section{References}

i. Alice, S. (2005). Module evaluation and feedback: Oxford Brookes University

ii. Applin, H., Williams, B., Day, R., \& Buro, K. (2011). A comparison of competencies between problem-based learning and non-problem-based graduate nurses. Nurse EducToday,31,129e134. http://dx.doi.org/10.1016/j.nedt.2010.05.003.

iii. Arthur, W. J., Tubre, T., Paul, D. S., \& Edens, P. S. (2003). Teaching effectiveness: The relationship between reaction and learning evaluation criteria. Educational Psychology, 23(3), 275.

iv. Canniford, L.J., \& Fox-Young, S. (2015). Learning and assessing competence in reflective practice: student evaluation of the relative value of aspects of an integrated, interactive reflective practice syllabus. Collegian, 22 (3), $291 \mathrm{e} 297$. http://dx.doi.org/10.1016/j.colegn.2014.04.003.

v. Curran, V.R., Sharpe, D., Flynn, K., \& Button, P. (2010). A longitudinal study of the effect of an interprofessional education curriculum on student satisfaction and attitudes towards interprofessional teamwork and education. J. Interprofessional Care, 24 (1), 41e52. http://dx.doi.org/10.3109/13561820903011927.

vi. Diefenbeck, C., Herrman, J., Wade, G., Hayes, E., Voelmeck, W., Cowperthwait, A., \& Norris, S. (2015). Preparedness for clinical: evaluation of the core elements of the clinical immersion curriculum model. J. Prof. Nurs. 31 (2), $124 \mathrm{e} 132$. http://dx.doi.org/10.1016/j.profnurs.2014.08.004.

vii. Emamzadeh Ghasemi, H. S., Rafii, F., Farahani, A. M., \& Mohammadi, N. (2014). Being at Peace as an Important Factor in Acquiring Teaching Competency by Iranian Nurse Teachers: A Qualitative Study. Global journal of health science, 6(3), p109. http://dx.doi.org/ 10.5539/gjhs.v6n3p109 
viii. Fitzpatrick, J. (2004). Evaluating teaching effectiveness. Nursing Education Perspectives, 25(3), 109.

ix. Fluit, C. R., Bolhuis, S., Grol, R., Laan, R., \& Wensing, M. (2010). Assessing the quality of clinical teachers. Journal of general internal medicine, 25(12), 1337-1345. http://dx.doi.org/10.1007/s11606-010-1458-y

x. Hasheesh, M. A., Al-Mostafa, O.\& Obeida, H. T. (2011). Traditional Versus Nontraditional Methods of Teaching: the Impact on Nursing Teaching Ronald. AnNajah Univ. J. Res. (Humanities), 25(1).

xi. Heshmati-Nabavi, F., \& Vanaki, Z. (2010). Professional approach: The key feature of effective clinical educator in Iran. Nurse Education Today, 30(2), 163-168. http://dx.doi.org/10.1016/j.nedt.2009.07.010

xii. Houser, J. (2008). Nursing Research: Reading, using and creating research. Denver: Jones \& Bartlett Publishers.

xiii. Kashaninia, Z., Rasuli, M., Hoseini, M., \& Kashef Ghorbanpor, R. (2013). Designing and psychometric analysis of the teaching evaluation scale. Journal of Nursing Education,2(2),21-29.Retrievedfrom http://en.journals.sid.ir/ViewPaper.aspx?ID=324731

xiv. Kong, L.-N., Qin, B., Zhou, Y-q., Mou, S-y., Gao, H.-M., 2014. The effectiveness of problem-based learning on development of nursing students' critical thinking: a systematic review and meta-analysis. Int. J. Nurs. Stud. 51, 458e469. http://dx.doi.org/10.1016/j.ijnurstu.2013.06.009.

xv. LoBiondo-Wood, G., \& Haber, J. (2013). Nursing research: Methods and critical appraisal for evidence-based practice. Elsevier Health Sciences.

xvi. Marquis, B., \& Huston, C. J. (2009). Leadership roles and management functions in nursing: Theory and application. Lippincott Williams \& Wilkins.

xvii. Mansoureh A. Farahani, Sadat, H., Emamzadeh ghasemi, Nikpeyma, N., Fereidouni, Z. \&Rassouli, M. (2015). Development and Psychometric Evaluation of the Nursing Instructors' Clinical Teaching Performance Inventory. Global Journal of Health Science, 7, (3).

xviii. Owen, S. (1992). Devising a checklist to evaluate the non- verbal aspects of teaching skills and delivery. Nurse Education Today, 12(5), 392-395.

xix. Patricia, Y., \& Nancy, D. (2002). Learning to lecture: exploring the skills, strategies, and practices of New Teachers. Nursing Education, 41(9).

xx. Ronald A. \& Berk. (2005). Survey of 12 Strategies to Measure Teaching Effectiveness International Journal of Teaching and Learning in Higher Education, 17(1), 48- $\quad 62 \mathrm{http}: / / w w w . i s e t l . o r g / i j t l h e / I S S N ~ 1812-9129$

xxi. Salsali, M. (2005). Evaluating teaching effectiveness in nursing education: An Iranian perspective BMC Medical Education, 5, 29. doi:10.1186/1472-6920-5-

xxii. Stronge, J. H. (2002). Qualities of effective teachers. Association for Supervision and Curriculum Development, 129. 


\section{Appendix}

Questionnaire for Post RN B.Sc. N Students

ID

INSTITUTE NAME

PART TIME / FULLTIME

COURSE

INVESTIGATOR

DATE

Consider each teaching element below and evaluate the teaching skills of the instructor by placing a check mark under the term best describing your evaluation of the instructor's actions. Give comments on individual points where you feel you have observed enough to make them.

\begin{tabular}{|c|c|c|c|}
\hline Class Organization The instructor: & $\begin{array}{c}1 \\
\text { Needs Improvement }\end{array}$ & $\begin{array}{c}2 \\
\text { Effective }\end{array}$ & $\begin{array}{c}3 \\
\text { Highly Effective }\end{array}$ \\
\hline \multicolumn{4}{|l|}{ 1. Started class on time. } \\
\hline 2. Introduced lesson (overview or focusing activity) & & & \\
\hline \multicolumn{4}{|l|}{ 3. Paced topics appropriately. } \\
\hline \multicolumn{4}{|l|}{ 4. Sequenced topics logically. } \\
\hline \multicolumn{4}{|l|}{ 5. Summarized or reviewed major lesson points. } \\
\hline \multicolumn{4}{|l|}{ 6. Ended class on time. } \\
\hline $\begin{array}{l}\text { Presentation } \\
\text { Instructor }\end{array}$ & Needs improvement & Effective & Highly effective \\
\hline \multicolumn{4}{|l|}{ 7. Presented or explained content clearly. } \\
\hline \multicolumn{4}{|l|}{ 8. Used good examples to clarify points. } \\
\hline \multicolumn{4}{|l|}{$\begin{array}{l}\text { 9. Varied explanations to respond to student } \\
\text { questions or needs for clarification. }\end{array}$} \\
\hline \multicolumn{4}{|l|}{ 10. Emphasized important points. } \\
\hline \multicolumn{4}{|l|}{$\begin{array}{l}\text { 11. Used graphics or visual aids or other } \\
\text { enhancements to support presentation. }\end{array}$} \\
\hline \multicolumn{4}{|l|}{ 12. Used appropriate voice volume and inflection } \\
\hline \multicolumn{4}{|l|}{$\begin{array}{l}\text { 13. Presented information or led discussions with } \\
\text { enthusiasm and interest. }\end{array}$} \\
\hline \multicolumn{4}{|l|}{$\begin{array}{l}\text { 14. Responded appropriately to student behaviors } \\
\text { indicating boredom or confusion. }\end{array}$} \\
\hline $\begin{array}{c}\text { Class interactions } \\
\text { The instructor }\end{array}$ & Need improvement & Effective & Highly effective \\
\hline \multicolumn{4}{|l|}{ 15. Encouraged student questions. } \\
\hline \multicolumn{4}{|l|}{$\begin{array}{l}\text { 16. Asked questions to monitor student } \\
\text { understanding. }\end{array}$} \\
\hline \multicolumn{4}{|l|}{$\begin{array}{l}\text { 17. Waited sufficient time for students to answer } \\
\text { questions }\end{array}$} \\
\hline \multicolumn{4}{|l|}{$\begin{array}{l}\text { 18. Provided opportunities for students to interact } \\
\text { together to discover/discuss or practice content } \\
\text { points. }\end{array}$} \\
\hline $\begin{array}{c}\text { Mastery of Content } \\
\text { The instructor: } \\
\end{array}$ & Need improvement & Effective & Highly effective \\
\hline \multicolumn{4}{|l|}{$\begin{array}{l}\text { 19. Presented content at an appropriate level for the } \\
\text { students. }\end{array}$} \\
\hline \multicolumn{4}{|l|}{$\begin{array}{l}\text { 20. Presented material relevant to the purpose of the } \\
\text { course. }\end{array}$} \\
\hline \multicolumn{4}{|l|}{ 21. Demonstrated command of the subject matter. } \\
\hline $\begin{array}{c}\text { Instructor Attitudes } \\
\text { The instructor } \\
\end{array}$ & Need improvement & Effective & Highly effective \\
\hline 22. Showed enthusiasm for the content & & & \\
\hline
\end{tabular}

